\title{
Conjunctival involvement in cicatricial and bullous pemphigoid: a clinical and immunopathological study
}

\author{
PEGGY A FRITH, ${ }^{1}$ V A VENNING, ${ }^{2}$ F WOJNAROWSKA, ${ }^{2}$ PR MILLARD ${ }^{3}$, \\ AND A J BRON'
}

From the 'Departments of Ophthalmology, Oxford Eye Hospital; ${ }^{2}$ Dermatology, Slade Hospital Oxford; and ${ }^{3}$ Histopathology, John Radcliffe Hospital, Oxford

SUmmary Patients with bullous pemphigoid were found to have significant ocular abnormalities. In a group of 18 patients one had conjunctival shrinkage, and 11 of $15(73 \%)$ had positive linear direct immunofluorescence on conjunctival biopsy from a clinically uninvolved site. Our ocular findings in a group of 14 with cicatricial pemphigoid are also reported and compared with those from a control group of 20 . Our findings suggest there is overlap between the pemphigoid groups and raise further questions about the pathogenicity of immunoreactants within the basement membrane zone. Bulbar conjunctival biopsy was simple and well tolerated, and the rate of immunofluorescence positivity of conjunctiva was twice that of skin in both pemphigoid groups.

The acquired subepidermal blistering (pemphigoid) dermatoses have been classified according to both clinical and pathological criteria ${ }^{12}$ but in practice this classification is not clear cut. Cicatricial pemphigoid (CP, also known as benign mucous membrane pemphigoid) affects chiefly the mucous membranes, where scarring in the eye or mouth is a necessary feature. ${ }^{2-7}$ Skin involvement is found in up to onethird of patients; it also tends to produce scarring but is rarely a major feature. By contrast, bullous pemphigoid (BP) is a non-scarring disease affecting chiefly the skin: mucosal involvement has been reported in the mouth ${ }^{8}$ but not previously in the eye. Immunopathological studies in the two disorders also suggest overlap. Tissue direct immunofluorescence (IMF) shows binding of immunoreactants to the basement membrane zone (BMZ) in a linear pattern in both groups. . $^{-19}$

Although conjunctival involvement, both clinical and immunopathological, has been well characterised in CP, it has not previously been reported in BP. We examined the eyes of 18 patients with BP looking for both clinical and immunopathological abnormalities. We report a comparison with $14 \mathrm{CP}$ patients and controls.

Correspondence to P A Frith, MRCP, Eye Hospital, Walton Street, Oxford OX2 6AN.
Patients and methods

PATIENTS

Patients were recruited from the dermatology and oral surgery departments and so were not known to have conjunctival involvement at the initial identification. They were defined as CP or BP as follows: if the disease affected predominantly the mouth or unequivocal skin scarring was found, the patients were defined as CP. If the skin was chiefly involved, without scarring but with positive direct IMF in skin at some stage of their illness, they were defined as BP.

The duration of disease in the pemphigoid patients varied from 19 years to 2 weeks, average 42 months. $30 \%$ were in clinical remission and $50 \%$ on systemic treatment at the time of biopsy. Fourteen patients with CP were assessed clinically, and conjunctival biopsies were obtained in 13 , eight of whom also had biopsies of skin and oral mucosa. In the BP group the figures were 18,15 , and 11 respectively.

As the study was critically concerned with evidence of conjunctival signs, a group of 20 age matched controls, drawn from routine preoperative patients (cataract, squint, and retinal surgery) were assessed similarly, though their status was not masked. A further seven control patients consented to conjunctival biopsy at the time of surgery. 
No patient, including controls, had a past history of confounding eye disorder known to cause conjunctivel scarring, such as injury, infection, atopy, or topical or systemic medication.

\section{CLINICAL ASSESSMENT}

The patients were assessed by an ophthalmologist (PF), who was unaware of their status (except of control patients), for full ocular history and examination including slit-lamp microscopy and conjunctival biopsy. They were asked about symptoms such as discomfort, redness, or itching of the eyes, and whether this was of mild, moderate, or severe degree. Slit-lamp examination at $16 \times$ magnification was carried out particularly to look for fine linear scarring of the tarsal conjunctiva, which might suggest early involvement in a cicatrising process. This was graded, according to a protocol, as just detectable, definite, moderate, or marked. Scarring with adhesions between tarsal and bulbar conjunctiva (symblepharon) was also looked for by simple eversion of the lids and the depth of the inferior fornix and presence of forniceal folds noted. The bulbar conjunctiva was assessed for clinical signs of active inflammation in terms of vascular dilatation, chemosis, and thickening.

\section{CONJUNCTIVAL BIOPSY}

Conjunctival biopsy was taken from a standard site in the upper temporal bulbar conjunctiva (thus from a clinically uninvolved site), using surface anaesthesia with oxybuprocaine drops. With slit-lamp viewing a $2 \mathrm{~mm}$ snip biopsy was taken which was embedded in optimal cutting temperature (OCT) medium and snap frozen in liquid nitrogen. Topical chloramphenicol ointment was applied to the eye for five days. Stitching was not necessary. Care was taken to do a biopsy prior to the use of topical fluorescein. Control specimens of conjunctiva were taken from seven patients at routine surgery (cataract, squint, or retinal) from the edge of the surgical incision and processed in the same way.
OTHER TISSUE BIOPSIES

Skin and oral mucosal biopsies were taken by punch technique with local anaesthesia from clinically uninvolved standard sites on the lower lip and volar forearm, and processed and examined in the same way.

\section{IMMUNOFLUORESCENCE}

Cryostat sections of the biopsy were prepared and were exposed to fluorescein isothiocyanate (FITC) labelled preparations of antihuman IgG, A, M, C3, $\mathrm{C} 4$, and C1q (Hoechst UK Ltd). The sections were examined with ultraviolet light for any fluorescence. Control sections for indirect immunolfluorescence (IMF) were prepared with unlabelled antibodies as blocking agents. The assessing pathologist (PM) was unaware of the patient's status.

\section{Results}

The ocular findings from 14 patients with $\mathrm{CP}$ and 18 patients with BP, compared with 20 control patients, are summarised in Table 1.

In our control group, matched for age, $40 \%$ reported minor ocular symptoms. Definite fine conjunctival scarring was found in $45 \%$, and mild bulbar conjunctival chemosis and reddening were common. Conjunctival IMF showed only non-linear staining with IgA within some of the surface epithelial cells in $71 \%$ of seven control biopsies.

In the $\mathrm{CP}$ group one patient with recent onset of severe mouth ulceration had troublesome eye symptoms, with moderate discomfort of both eyes, . and had noticed mild redness and stickiness of the right eye only. She had moderately reddened and chemosed conjunctiva and focal lower tarsal conjunctival ulceration in the right eye only. She did not show ocular scarring, and seemed to be an early presentation of CP simultaneously involving mouth and eyes. Otherwise, conjunctival signs in the CP group were not reliably correlated either with symptoms or with IMF findings, including the presence of

Table 1 Ocular findings in cicatricial and bullous pemphigoid and control patients

\begin{tabular}{|c|c|c|c|c|c|c|c|}
\hline \multirow{3}{*}{$\begin{array}{l}\text { Clinical diagnosis } \\
\text { (no. of patients) }\end{array}$} & \multicolumn{4}{|c|}{ Clinical findings } & \multicolumn{3}{|c|}{ Immunopathological findings } \\
\hline & \multirow{2}{*}{$\begin{array}{l}\text { Age in years, } \\
\text { average }\end{array}$} & \multirow{2}{*}{$\begin{array}{l}\text { Ocular } \\
\text { symptoms } \\
\%\end{array}$} & \multirow{2}{*}{$\begin{array}{l}\text { Linear tarsal } \\
\text { scarring } \\
\%\end{array}$} & \multirow{2}{*}{$\begin{array}{l}\text { Conjunctival } \\
\text { shrinkage or } \\
\text { symblepharon } \\
\text { No. of patients }\end{array}$} & \multicolumn{2}{|c|}{ Linear deposit at $B M Z$} & \multirow{2}{*}{$\begin{array}{l}\text { Non-linear } \\
\text { intraepithelial } \\
\%\end{array}$} \\
\hline & & & & & No. & $\%$ & \\
\hline CP (14) & 65 & 62 & 28 & 2 & 13 & 46 & 77 \\
\hline BP (18) & 74 & 56 & 39 & 1 & 15 & 73 & 67 \\
\hline Control (20) & 61 & 40 & 45 & 0 & $7^{*}$ & $0^{*}$ & $71 *$ \\
\hline
\end{tabular}

*Obtained from seven separate control patients. 
Table 2 Immunopathology of conjunctival biopsies in cicatricial and bullous pemphigoid and control patients

\begin{tabular}{|c|c|c|c|c|c|c|c|c|}
\hline \multirow{2}{*}{$\begin{array}{l}\text { Clinical } \\
\text { diagnosis } \\
\text { (no. of } \\
\text { patients) }\end{array}$} & \multicolumn{4}{|c|}{ Linear at $B M Z(\%)$} & \multicolumn{4}{|c|}{ Non-linear intraepithelial (\%) } \\
\hline & $\lg G$ & $\operatorname{Ig} A$ & IgM & $C 3$ & $\lg G$ & $\operatorname{Ig} A$ & $\lg M$ & C3 \\
\hline $\mathrm{CP}(13)$ & $5(38)$ & $1(8)$ & 0 & $3(23)$ & 0 & $10(77)$ & $3(23)$ & 0 \\
\hline BP & $8(53)$ & 0 & $\mathbf{0}$ & $7(47)$ & 0 & $11(73)$ & 0 & 0 \\
\hline Control (7) & & 0 & 0 & 0 & 0 & $5(71)$ & $1(14)$ & 0 \\
\hline
\end{tabular}

$\mathrm{C} 4$ and $\mathrm{Clq}$ were negative in all specimens.

C3. Definite fine linear scarring was found in the lower tarsal conjunctiva in four $(28 \%)$, which was no higher than in the control group. Symblepharon was found in two asymptomatic CP patients $(14 \%)$. If fine linear scarring was included as a significant feature, evidence of a cicatrising conjunctival disorder was found in six patients $(43 \%)$.

In the CP group conjunctival IMF showed a positive linear pattern at the $B M Z$ in six of 13 patients biopsied (46\%). Two patients showed IgG alone, one patient $\mathrm{C} 3$ alone, two patients both $\mathrm{IgG}$ and $\mathrm{C} 3$ together, and one patient IgG and IgA together. $\operatorname{IgA}$ was also found in a non-linear pattern, as in controls, within some of the epithelial cells in $77 \%$ (Table 2).

In the 18 patients classified as BP minor clinical symptoms were reported by $56 \%$. No patient had troublesome symptoms. Definite fine tarsal conjunctival scarring was seen in $39 \%$ as a non-specific finding. However, one patient had loss of inferior forniceal folding, with shrinkage of the lower conjunctival sacs bilaterally, though there was no focal symblepharon (Fig. 1).

Conjunctival IMF in the BP group showed linear deposition of immunoreactants at the $\mathrm{BMZ}$ in 11 of

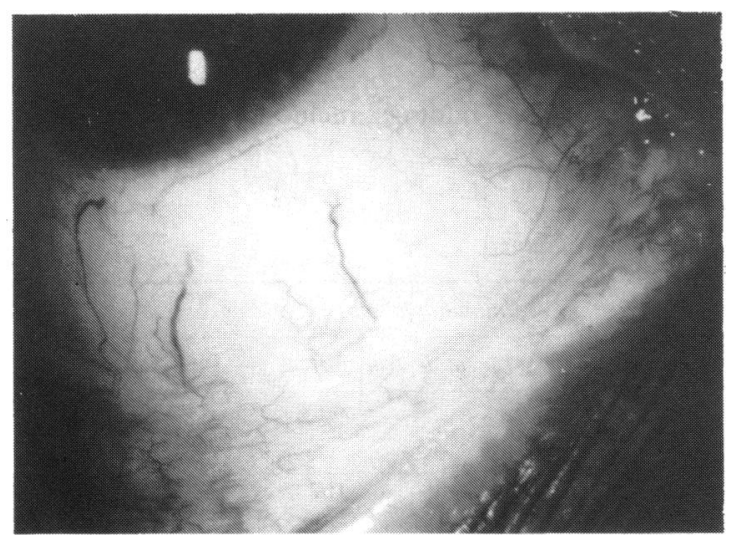

Fig. 1 Eye of bullous pemphigoid patient showing shrinkage of lower conjunctival fornix with loss of forniceal folding.

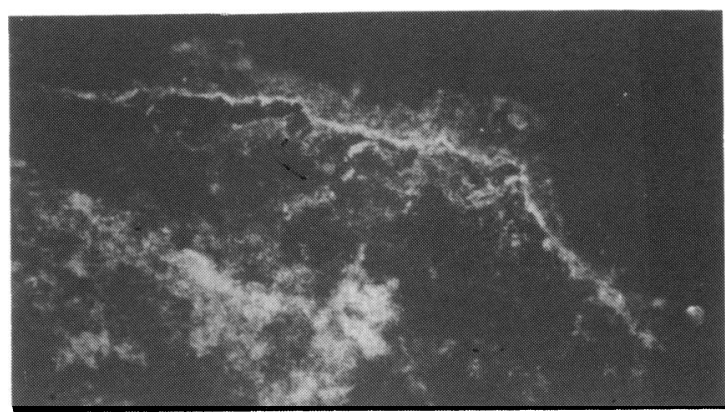

Fig. 2 Conjunctival direct immunofluoresence in bullous pemphigoid showing linear IgG deposition along basement membrane zone.

$15 \mathrm{BP}$ patients biopsied ( $73 \%$ positive). Four of these showed IgG alone (Fig. 2), three C3 alone, and four both IgG and C3 together (Table 2).

Table 3 summarises the prevalence of positive linear IMF in the three different tissues biopsied in eight $\mathrm{CP}$ and $11 \mathrm{BP}$ patients.

Thus overall conjunctiva yielded the highest rate of positive IMF in both CP and BP patients, with over double the rate found in skin in both groups despite initial presentation in skin or mouth rather than the eye.

\section{Discussion}

Previous studies have reported clinical ${ }^{1-8}$ or immunopathological ${ }^{9-22}$ conjunctival features of the pemphigoid groups, but no single study has looked systematically at both features in skin, mouth, and eye. Deposition of immunoglobulins or complement in a linear pattern at the $\mathrm{BMZ}$ appears to be specific for these groups. ${ }^{1622}$

The features of the conjunctival cicatrising disorder in CP have been described ${ }^{3-7}$ and distinguished from those found in other disorders. Wright ${ }^{5}$ describes three groups of features which may overlap. Acute appearances are conjunctival injection with ulceration which stains with fluorescein. One of our patients presented with this pattern. Intact blisters are rarely seen, though the patient may report them. Advanced disease shows symblepharon, which may be accompanied by sicca, lid deformity, trichiasis,

Table 3 Cicatricial and bullous pemphigoid: positive linear direct IMF at BMZ in three different tissues

\begin{tabular}{llll}
\hline $\begin{array}{l}\text { Clinical diagnosis } \\
\text { (no. of patients) }\end{array}$ & \multicolumn{4}{l}{ \% Positive linear direct IMF at BMZ } \\
\cline { 2 - 4 } & Conjunctiva & Lip mucosa & Skin \\
\hline CP $(8)$ & 46 & 40 & 20 \\
BP $(11)$ & 73 & 52 & 37 \\
\hline
\end{tabular}


and secondary corneal changes. There is a further group, often asymptomatic, with less obvious scarring of symmetrical conjunctival forniceal shrinkage, and loss of normal canthal architecture.

We observed fine linear scarring, usually of the central lower tarsal conjunctiva, which has been described in infective or atopic disease, where it may progress to shallowing of the fornix. ${ }^{7}$ We looked specifically to see if this was a significant early feature in our CP group with oral or cutaneous scarring. It was found in $28 \%$, but also in $45 \%$ of age matched controls, and so is not a specific finding. Moreover, we found that patients with symblepharon lacked this feature, making it unlikely that one precedes the other. Further follow-up of our patients may clarify its significance in $\mathrm{CP}$ patients.

Symblepharon itself did appear to be a significant form of scarring, and was found in two (14\%) of CP patients who had presented with mouth involvement but were free of ocular symptoms. Our CP group overall thus showed a lower incidence of scarring ( $43 \%$ if fine linear scarring was included) than previous studies of a similar group, presenting to non-ophthalmologists, ${ }^{6}$ which had evidence of a cicatrising conjunctival disorder in $67 \%$.

Despite a low incidence of clinical features we found positive IMF in the conjunctiva in $46 \%$ of our CP patients. This compares with previous reports of between $20 \%$ and $67 \%$ conjunctival positivity. ${ }^{9-6}$ However, the finding of conjunctival immunoreactants did not correlate with clinical features: one patient who presented acutely showed linear deposition of IgG and C3, as did two patients with symblepharon, but the other three IMF-positive patients lacked any significant symptoms or signs. It has also been suggested that scarring in $\mathrm{CP}$ may prevent binding of immunoreactants by destruction of the BMZ antigen involved, but finding positive IMF in clinically uninvolved tissue in both patients who had symblepharon suggests the antigen persists in this site.

In our BP group conjunctival scarring with shrinkage of the lower fornix was found in one patient whose skin features were typical of BP. This has not previously been reported in $\mathrm{BP}$, as it has perhaps been assumed that ocular scarring is a feature only of $\mathrm{CP}$, and the eyes of BP patients may not have been examined in detail. This patient conforms with Wright's description of asymptomatic changes in $\mathrm{CP}$ patients. ${ }^{5}$ Our finding further suggests confusion in the clinical definition of the two groups with overlap between them.

Immunopathologically our BP group showed a higher rate of positivity than the CP group in all tissues biopsied. The low rate of skin positivity in our BP patients (37\%) than in previous reports ${ }^{2021}$ may reflect the long average duration of disease and clinical mildness in our group at the time of biopsy. Despite this we found in the conjunctiva a surprisingly high rate $(73 \%)$ of positivity. This compared with $52 \%$ positivity from clinically uninvolved lip mucosa in the same patients (Table 3 ). The results of clinical and IMF comparison in these three sites have been presented in abstract and are to be described in a separate paper. ${ }^{2324}$ Linear deposition of immunoreactants has been found in the oesophagus and stomach, but not more distally in the gastrointestinal tract in $\mathrm{BP},{ }^{25}$ suggesting that the $\mathrm{BP}$ antigen is present only in stratified epithelia.

The distribution of IMF positivity between the three tissues and the class of immunoreactant found were of interest. Nineteen patients had all three tissues biopsied. In four of these all tissues were negative. In four all tissues were positive, with a similar class of immunoreactant found in all sites. It remains to be established whether the tissue immunoglobulins are identical and if they are the same as circulating anti-basement-membrane zone antibodies, which may be found in patients in both groups. ${ }^{212-15}$ In six patients uninvolved bulbar conjunctiva was the only source of positive material. The conjunctiva is thus a useful site to examine for diagnostic purposes, particularly in BP, though a definite diagnosis may not be made from this site alone, as $27 \%$ are IMF-negative in clinically uninvolved conjunctiva. In $\mathrm{CP}$ the rate of positivity is lower, and it may be useful to examine the skin and lip also in patients who present with eye involvement; in two $\mathrm{CP}$ patients the conjunctiva was negative for IMF when skin and lip were positive.

In all groups of patients and the controls $\operatorname{IgA}$ was found in about $75 \%$ of biopsies in a non-linear fashion within some of the conjunctival epithelial cells. The significance of this is unknown, but it may represent locally produced IgA adsorbed from tears into the epithelial cells. The appearance has been previously reported.$^{14} \mathrm{We}$ have looked for secretory piece (the glycopolypeptide which is normally attached to IgA secreted on to mucosal surfaces) in these biopsies (Millard unpublished) with negative results. Further studies into its origin are planned.

We have found bulbar conjunctival biopsy to be simple and well tolerated, though it does ideally require slit-lamp facilities. Most patients found it painless, and there was usually no bleeding. There were no complications apart from a single patient in the $\mathrm{CP}$ group who returned with a red painful eye three days after biopsy. She was found to have focal inflammation at the site of biopsy, probably due to too deep a sample, which had included episclera. This rapidly settled with continued topical antibiotic alone. Only two patients refused biopsy. Our sample 
size was adequate for a full set of tests, and did not require specific orientation. Other authors have stressed that biopsy of the fornix from a clinically involved site may be hazardous. ${ }^{726}$

Our findings suggest further overlap between $\mathrm{CP}$ and $B P$, as we found significant though often asymptomatic ocular abnormalities in both groups. The $73 \%$ positive linear IMF in conjunctiva in $\mathrm{BP}$ is an unexpected finding, as it does not correlate with clinical features. This raises further questions about the pathogenicity of immunoreactants within the BMZ. We suggest that biopsy of uninvolved bulbar conjunctiva is an acceptable and valuable technique for diagnosis in the pemphigoid group.

\section{References}

1 Lever WF. Pemphigus. Medicine (Baltimore) 1953; 32: 1-123.

2 Person JR, Rogers RS. Bullous and cicatricial pemphigoid: clinical histopathological and immunopathological correlations. Mayo Clin Proc 1977; 52: 54-66.

3 Hardy KM, Perry KO, Pingree GC, Kirby TJ. Benign mucous membrane pemphigoid. Arch Dermatol 1971; 104: 467-75.

4 Jones BR. The ocular diagnosis of benign mucous membrane pemphigoid. Proc R Soc Med 1961; 54: 109-10.

5 Wright $P$. The enigma of ocular cicatricial pemphigoid. Trans Ophthalmol Soc UK 1979; 99: 141-5.

6 Leonard JN, Wright P, Williams DM, et al. The relationship between linear IgA disease and benign mucous membrane pemphigoid. Br J Dermatol 1984; 110: 307-14.

7 Wright P. Cicatrising conjunctivitis. Trans Ophthalmol Soc UK 1986; 105: 1-17.

8 Shklar G, Meyer I, Zacarian SA. Oral lesions in bullous pemphigoid. Arch Dermatol 1969; 99: 663-70.

9 Bean SF, Waisman M, Michel B, Thomas CI, Knox JM, Levine M. Cicatricial pemphigoid. Immunofluorescent studies. Arch Dermatol 1972; 106: 195-9.

10 Griffith MR, Fukuyama K, Tuffanelli D, Silverman S. Immunofluorescent studies in benign mucous membrane pemphigoid. Arch Dermatol 1974; 109: 195-9.
11 Herron BE. Immunologic aspects of cicatricial pemphigoid. Am J Ophthalmol 1975; 79: 271-8.

12 Furey N, West C, Andrews T, Paul PD, Bean SF. Immunofluorescence studies in ocular cicatricial pemphigoid. $A m J$ Ophthalmol 1975; 80: 825-31.

13 Bean SF, Furey N, West CE, Andrews T, Esterly NB. Ocular cicatricial pemphigoid. Ophthalmology 1976; 81: 806-12.

14 Mondino BJ, Ross AN, Rabin BS, Brown SI. Autoimmune phenomena in ocular cicatricial pemphigoid. Am J Ophthalmol 1977; 83: 443-50.

15 Fine JP, Neises GR, Katz SI. Immunofluorescence and immunoelectron microscopy in cicatricial pemphigoid. $J$ Invest Dermatol 1984; 82: 39-43.

16 Leonard JN, Hobday C, Griffiths CEM, et al. Immunofluorescent studies in ocular cicatricial pemphigoid. $\mathrm{Br} J$ Dermatol 1987; 116: 431.

17 Rogers RS, Jordon RE. Immunopathology of oral mucosal inflammatory diseases. Clin Exp Dermatol 1977; 2: 97-107.

18 Rogers RS, Perry HO, Bean SF, Jordon RE. Immunopathology of cicatricial pemphigoid. J Invest Dermatol 1977; 68: 39-43.

19 Laskaris G, Nocolis G. Immunopathology of oral mucosa in bullous pemphigoid. Oral Surg 1980; 50: 340-5.

20 Jordon RE, Beutner EH, Witebsky E, Blumental G, Hale WL, Lever WF. Basement membrane zone antibodies in bullous pemphigoid. JAMA 1967; 200: 751-6.

21 Jordon RE, Schroefer AL, Good RA, Day NK. The complement system in bullous pemphigoid. Clin Immunol Immunopathol 1975; 3: 307-14.

22 Rogers RS, Van Hale HM. Immunopathologic diagnosis of oral mucosal inflammatory diseases. Aust J Dermatol 1986; 27: 51-7.

23 Venning VA, Frith PA, Bron AJ, Millard PR, Wojnarowska F. Ocular and oral involvement in bullous and cicatricial pemphigoid. Br J Dermatol 1986; 115: 19-20.

24 Venning VA, Frith PA, Bron AJ, Millard PR, Wojnarowska F. Mucosal involvement in bullous and cicatricial pemphigoid: a clinical and immunopathological study. $\mathrm{Br} J$ Dermatol in press.

25 Bernard P, Souyn N, Pillegand B, Bonnetblanc JM. Immunofluorescence studies of the gastrointestinal tract in bullous pemphigoid. Arch Dermatol 1986; 122: 137-8.

26 Andersen SR, Jensen OA, Kristensen EB, Norn MS. Benign mucous membrane pemphigoid: biopsy. Acta Ophthalmol (Kbh) 1974; 52: 455-63.

Accepted for publication 26 November 1987. 